\title{
PROBLEMAS E RISCOS ENFRENTADOS EM PROJETOS DE ROLLOUT GLOBAL DO ERP SAP
}

\author{
Ana Carolina de Gouvêa Dantas Motta ${ }^{1}$ \\ Professora do Mestrado Profissional - MPGTQAC/USU \\ anacarolinadegouvea@gmail.com \\ Rafael Ruszynski Hecksher \\ Instituto INFNET \\ emiliano.castor@gmail.com \\ Robson Araújo Bordalo \\ Instituto INFNET \\ emiliano.castor@gmail.com \\ Emiliano Carlos Serpa Castor ${ }^{3}$ \\ Universidade Santa Úrsula \\ Instituto INFNET \\ emiliano.castor@gmail.com
}

\begin{abstract}
Resumo
A concorrência cada vez mais intensa entre as empresas no mundo globalizado, e com um mercado consumidor cada vez mais exigente, levaram as empresas a buscar na gestão da informação um diferencial competitivo para sobreviver dentro do negócio. Diante do exposto, os softwares de gestão integrada ERP (Enterprise Resource Planning) passaram a ser utilizados como ferramenta de gestão empresarial com o objetivo de aumentar os lucros através da integração das informações. Este trabalho aborda os riscos e impactos no rollout de um sistema ERP e a sua importância na tomada de decisões nas empresas. Para isto foi realizada uma pesquisa bibliográfica contextualizando a introdução do software no mundo empresarial, a definição de ERP e o cenário empresarial da região. A pesquisa foicomplementada com um estudo de caso único em uma empresa do ramo refratário. A pesquisa de caráter qualitativo, exploratório e descritivo aborda os principais aspectos da implementação do ERP com dados históricos da implementação na referida empresa e através de entrevistas com os funcionários responsáveis, pretendeu analisar os requisitos e retornos da implementação bem como as funcionalidades do software SAP. A pesquisa demonstra que apesar das dificuldades enfrentadas, os benefícios obtidos com a implementação do ERP são compensatórios.
\end{abstract}

Palavras-chave: Sistema Integrado de Gestão. ERP. Go Live. Rollout.

\footnotetext{
${ }^{1}$ Doutora em Engenharia de Produção - COPPE/UFRJ; Professora do Mestrado Profissional - MPGTQAC/USU.

${ }^{2}$ Graduação em Engenharia de Alimentos pela Universidade Federal Rural do Rio de Janeiro (1996), graduação em Engenharia de Alimentos pela Universidade Federal Rural do Rio de Janeiro (1996), mestrado em Engenharia de Produção pela Universidade Federal Fluminense (2006) e ensino-medio-segundo-grau pelo Colegio Belisario dos Santos (1991).

${ }^{3}$ Graduação em Sequencial em Automação e Robótica pela Universidade Santa Úrsula (2001), graduação em Engenharia de Computação pela Universidade Santa Úrsula (2001), graduação em Licenciatura em Matemática pelo Instituto A Vez do Mestre (2015), graduação em Matemática pela Universidade do Estado do Rio de Janeiro (2004) e mestrado em Gestão do Trabalho para a Qualidade do Ambiente Construído pela Universidade Santa Úrsula (2017). Atualmente é especialista sap - Ilumno, professor auxiliar do Centro Universitário Moacyr Sreder Bastos, professor da Universidade Santa Úrsula, professor titular do Instituto Infnet do Rio de Janeiro e coordenador de pós-graduação lato sensu do Instituto Infnet do Rio de Janeiro. Tem experiência na área de Ciência da Computação, com ênfase em Ciência da Computação, atuando principalmente nos seguintes temas: sap, erp, hcm, recursos humanos e orgpublisher.
} 


\title{
PROBLEMS AND RISKS FACED IN GLOBAL ROLLOUT OF TEMPLATE SAP ERP
}

\begin{abstract}
The competition increasingly intense among the companies in the globalized world, and with an increasingly demanding consumer market over the last decades have led companies to seek the information management a competitive edge to survive in the business. Given the above, ERP integrated management software (Enterprise Resource Planning) now used as a business management tool in order to increase profits by integrating information. This study aimed to address the risks and impact on the rollout of an ERP system and its importance in decisionmaking in business. In order to accomplish that goal, we made a bibliographical research contextualizing the introduction of software in the business world, the definition of ERP and business environment of the region. The research was complemented by a single case study of a company in the refractory industry. A qualitative, exploratory and descriptive research addresses the main aspects of the implementation of ERP with historical implementation data in this company and through interviews with the responsible officials, aimed to analyze the implementation of the requirements and returns as well as the SAP software functionality. Research shows that despite the difficulties encountered, the benefits gained from the implementation of ERP are compensatory.
\end{abstract}

Keywords: Integrated Management System. ERP. Go Live. Rollout.

\section{INTRODUÇÃO}

Diante de um cenário tecnológico mundial com diversas inovações, as empresas buscam diariamente novas tecnologias, e recursos para estarem à frente de seus concorrentes, sempre com o objetivo de minimizar seus custos, e ampliar os seus resultados no mundo coorporativo.

A abordagem utilizada neste trabalhobuscou contribuir com a compreensão de como um projeto de rolloutdo sistema ERP SAP pode vir aimpactar a empresa contratantedurante sua implantação. Em outras palavras, descrever quais os riscos, e problemas encontrados, que possam impactar o tempo, custo e qualidade de entrega do projeto.

A metodologia utilizada foi a pesquisa descritiva, e os instrumentos de pesquisa foram a análise documental, questionários e observação participante.

A pesquisa realizada apontou algumas variáveis e informações de risco na qual destacam-se a resistência por parte de seus usuários, a mudança cultural dentro da empresa, o planejamento de atividades (Overlapping/ FastTracking), e principalmente por se tratar de um projeto global, a diferença entre as culturas dos países participantes (Brasil, França, Alemanha, China e Argentina).

Deste modo foi utilizado um estudo de caso real de um rollout global do ERP SAP em uma empresa do ramo de refratário. Com isso, espera-se apontar possíveis problemas, que por falta de planejamento, ou erro de execução poderiam ser evitados ou corrigidos sem a necessidade de prorrogação da data do Go Live do projeto. 


\subsection{O PROBLEMA}

O gerenciamento de projetos consiste na aplicação de conhecimentos, habilidades, ferramentas e técnicas adequadas às atividades do projeto, a fim de cumprir seus requisitos e metas. $\mathrm{O}$ ato de analisar o andamento de um projeto é importante na medida em que, por meio dele, se observam os possíveis impedimentos, restrições ou dificuldades relativas à realização das atividades do projeto. Tal observação implica em possíveis ações corretivas e preventivas, sempre na tentativa de remover completamente os impedimentos e garantir a boa execução do que foi planejado.

Nenhum projeto está livre de riscos e problemas. Um risco é uma condição que, caso venha a ocorrer, pode comprometer ou impedir a realização de um projeto. Já um problema é uma questão que se propõe a ser resolvida mediante alternativas. Logo, é fácil compreender porque um conjunto de problemas relacionados constitui um risco agregado a um projeto.

A natureza dos problemas associados a projetos é de ordem mais diversa, mas há uma série deles mapeados como mais comuns em projetos, dentre os quais se destacam: complexidade do projeto, gerenciamento ineficiente ou amador, excesso de conflito entre os membros da equipe de projeto, falta de planejamento ou planejamento deficiente, objetivos mal definidos, excesso de alteração de escopo, incertezas e riscos, mudanças tecnológicas, estimativas de prazo e custo mal elaboradas e falta de controle ou controle ineficiente.

Dentro deste contexto, será abordado como todos os problemas mencionados acima podem levar um projeto a "abortar sua missão", ou no jargão da área de TI, dar No Go, e em alguns casos, perder o rumo.

Por essa razão, os gerentes de projetos, e principalmente as organizações também precisam conhecer e compreender detalhadamente suas atividades, as competências e habilidades de seus colaboradores e a inter-relação que há entre todos os setores da empresa para poder elaborar um projeto eficiente de implementação do SAP. Todos os envolvidos devem estar completamente, dedicados, e motivados para que o projeto tenha um resultado positivo.

Com base nisso, a pergunta de pesquisa deste estudo é: Quais os problemas e riscos enfrentados em projetos de rollout global do ERP SAP?

\subsection{OBJETIVOS}

Analisar os problemas e riscos enfrentados em projetos de rollout global do ERP SAP. 
A escolha do tema, foi devido a carência de gestão eficiente nos projetos SAP. Com isso, poderemos verificar e analisar os principais motivos que levam um projeto SAP a ter sua data de Go Live postergada.

\subsubsection{Objetivos gerais}

Este trabalho teve como objetivo identificar, analisar, pesquisar, e principalmente apurar em detalhes, o que levam os gerentes de projetos anunciarem o atraso de um projeto de rollout para sua equipe, e para empresa contratante.

Dentre todos os pontos abordados, inclusive utilizando estudo de caso, serão apresentadas algumas técnicas, e abordagens para se evitar que erros comuns que ocorrem em projetos SAP, ou ao menos, minimizar os impactos no Go livedo sistema.

\subsubsection{Objetivos intermediários}

Para alcançar o objetivo geral desta pesquisa, é necessário atingir os seguintes objetivos intermediários:

- Analisar a complexidade do projeto;

- verificar as possíveis falhas de gestão, ou amadorismo;

- analisar o excesso de conflitos entre os membros da equipe do projeto;

- identificar falhas no planejamento (tempo, custo, escopo e qualidade);

- analisar a alteração, e a inclusão de escopo;

- analisar riscos e incertezas que possam prejudicar o andamento do projeto;

- identificar falta, e disponibilidade dos recursos do projeto;

- analisar a eficácia no processo de comunicação; e

- apresentar um estudo de caso real de um rollout de um projeto SAP.

Todo os pontos mencionados acima, são extremamente importantes para que se obtenha o sucesso em todas as fases de um projeto. Isto é, não adianta planejar, se não souber colocar em prática, e executar as atividades com perfeição de acordo com o que foi solicitado pelo cliente. 


\subsection{SUPOSIÇÃO OU HIPÓTESE}

Devido a gama variada de problemas que podemos encontrar nos projetos, podemos dizer que hipoteticamente um dos maiores fatores para um insucesso dentro de um projeto de rollout SAP, inclusive descrito na análise do estudo de caso, está relacionado à chamada restrição tripla (Escopo, Tempo e Custo) apontada como o principal problema nos projetos e causa dos insucessos.

\subsection{DELIMITAÇÃO}

A pesquisa está delimitada à empresa estudada, isto é, não é pretensão desta pesquisa comparar o processo de análise de problemas em rollout's do ERP SAP com outras empresas.

Além disso, o enfoque deste estudo restringe-se apenas nos rollout'srealizados na referida organização em seus escritórios localizados na França e na Alemanha. Os demais rollout'socorridos em outras unidades não serão considerados como análise para este estudo.

O tempo também pode ser considerado uma delimitação deste estudo, o que torna esta análise válida apenas para o projeto de rollout ocorrido na empresa entre os anos de 2013 até 2015. Neste período, temos que considerar que a única unidade da empresa já utiliza o sistema, implantando em 2008, situa-se no Brasil. Os demais países, França e Alemanha são considerados como foco deste estudo.

As informações apresentadas abaixo também caracterizam esta pesquisa, a saber:

- o sistema em estudo será o ERP SAP 6.0. Não serão abordados assuntos, e metodologias de outros sistemas implementados na empresa estudada;

- as conclusões obtidas não deverão ser generalizadas para outros objetos de estudo, uma vez que o estudo de caso não possui pretensões estatísticas de representatividade de um universo;

- as informações estratégicas não serão divulgadas em decorrência de um acordo de confidencialidade estabelecido entre o pesquisador e a empresa pesquisada; e, por fim,

- a restrição na pesquisa (questionário) com os participantes do projeto, devido a indisponibilidade, e falta de tempo de alguns usuários. 


\subsection{JUSTIFICATIVA: TEÓRICA E PRÁTICA}

Tendo em vista o grande aumento de projetos ERP no mundo, considera-se relevante um estudo buscando aprofundar o conhecimento sobre os maiores problemas e riscos encontrados em um projeto de rollout do sistema ERP SAP.

Um dos principais motivos pela escolha deste tema é pelo fato de um dos maiores problemas estarem ligado diretamente à falta de liderança e ao gerenciamento ineficaz em projetos SAP. Outro ponto referente ao presente estudo justifica-se pelo fato de haver pouca bibliografia específica, e pesquisas científicas nas universidades sobre o assunto relacionado à projetos de rollout SAP.

A escolha deste assunto deve-se também ao fato de os pesquisadores envolvidos nesse estudo trabalharem na área de consultoria SAP, e com ampla experiência em projetos. Portanto, considerou-se oportunoesse estudo baseado em projetos, e problemas vivenciados por eles durante a sua carreira em rollouts de projetos SAP.

De acordo com a instituição PMSURVEY.ORG, em 2014 foi efetuado um levantamento em 400 organizações, onde $96 \%$ declararam ter problemas no comprimento com o prazo em seus projetos.

Aponta-se como exemplo a menção feita por Ricardo Vargas (2009), no artigo "Os Principais Problemas do Gerente de Projetos", onde destaca os principais problemas relacionados a gestão de projetos, a saber: falta de liderança, falta de entendimento do escopo, falta de recursos qualificados e motivados, falta de patrocinador, excesso e mal gerenciamento do poder na gestão de projetos.

Muitos dos problemas já temos conhecimentos, porém o interessante é analisar porque com ao passar do tempo, os problemas continuam os mesmos, e nenhuma ação é executada pelos gestores para reverter tal situação. Como podemos de alguma maneira, utilizar ferramentas, e metodologias corretas para evitar erros, e impactos nos projetos de rollout SAP.

Com base no PMBOK, e em alguns relatos e pesquisas, será possível identificar, analisar, e apresentar possíveis solução que não são consideradas, ou que tem pouca importância, porém que no final das contas podem evitar impactos, e trazer benefícios para a gestão de projeto.

Em que ponto uma gestão ineficaz pode levar o projeto ao adiamento de prazos, aumento dos custos, e até mesmo um "No Go" para o projeto. 
A contribuição deste estudo, do ponto de vista acadêmico, é prover aos estudantes e professores um caso prático de um rollout do ERP SAP em uma empresa de refratário e mostrar os benefícios do sistema e as barreiras encontradas no processo de implantação.

\subsection{METODOLOGIA}

Neste momento foi relatado de que maneira a pesquisa foi realizada, o instrumento utilizado para coleta de dados, o cenário e os sujeitos participantes da investigação.

O método científico utilizado para esta pesquisa é o método descritivo. Este tipo de pesquisa ocorre quando se registra, analisa e correlaciona fatos ou fenômenos, sem manipulálos (CERVO; BERVIAN; DA SILVA, p. 79, 2007). O tipo de pesquisa que se classifica como "descritiva", envolve o uso de técnicas padronizadas de coleta de dados: questionário e observação sistemática. (GIL, 2002). Esse método foi selecionado para esta pesquisa, com a finalidade de observar, analisar, e registrar os processos de implantação do SAP na empresa estudada.

O delineamento da pesquisa foi efetuado por meio de estudo de caso abordando o detalhamento de uma situação específica. Este estudo, consiste na utilização de um ou mais métodos qualitativos de recolha de informação e não segue uma linha rígida de investigação.

De acordo com Gil (2002), o elemento mais importante para a identificação de um delineamento é o procedimento adotado para a coleta de dados e, nesse caso, as principais fontes de dados utilizadas na pesquisa serão as pessoas e alguns documentos, caracterizando o Estudo de Caso.

Os instrumentos de pesquisa são, de acordo com Raupp e Beuren (2003), preceitos ou processos que o cientista deve utilizar para direcionar, de forma lógica e sistêmica, o processo de coleta, análise e interpretação dos dados. Neste trabalho, foram empregados os instrumentos de análise documental, questionários e, principalmente, a observância participante, que consiste na participação real do pesquisador com a comunidade ou grupo que está estudando.

Os questionários foram direcionados para usuários-chave específicos de cada processo interno da empresa e ao gerente do projeto de implantação do ERP, onde foram analisadas todas as respostas.

De modo geral, pode-se seguir a distinção proposta por Ferrari (1982), que afirma que a pesquisa qualitativa busca verificar se uma determinada característica está presente na população pesquisada, enquanto que a quantitativa deseja verificar a frequência com que essa característica ocorre nessa população. Assim, em relação à análise dos dados, a pesquisa 
classifica-se como qualitativa. Uma vez que a análise qualitativa tem por base conhecimentos teórico-empíricos que permite atribuir-lhe cientificidade.

\section{REFERENCIAL TEÓRICO}

\subsection{SISTEMAS ERP}

Compreende-se por Enterprise Resource Planning - ERP, ou Planejamento de recurso corporativo, um sistema de informação que integra todos os dados e processos de uma organização em um único lugar. A integração pode ser vista sob a perspectiva funcional, abrangendo sistemas de finanças, contabilidade, recursos humanos, fabricação, marketing, vendas, compras; e sob a perspectiva sistêmica, considerando, por exemplo, sistemas de processamento de transações, sistemas de informações gerenciais, sistemas de apoio a decisão (TURBAN, 2010).

O ERP controla a empresa, manuseando e processando suas informações. Todos os processos são documentados e contabilizados, gerando regras de negócio bem definidas e permitindo maior controle sobre alguns pontos vulneráveis do negócio, como a administração de custos, controle fiscal e estoques. A adoção desses sistemas põe fim aos vários sistemas que funcionavam de forma isolada na empresa, com informações redundantes e não confiáveis (MILTELLO, 1999).

Deste modo, um sistema ERP propõe essencialmente, eliminar a redundância de operações e burocracia ao automatizar os processos. Os módulos de um ERP permitem desenvolver e gerir o negócio de forma integrada. As informações são mais consistentes, permitindo uma melhor tomada de decisão, com base em dados reais. Para muitas empresas, estes benefícios traduzem-se em grandes benefícios de produtividade e rapidez (DAVENPORT, 1998).

\subsection{A IMPORTÂNCIA DO ERP NAS CORPORAÇÕES E EMPRESAS}

O ERP pode ser visto como um grande banco de dados com informações que interagem e se realimentam. Assim, o dado inicial sofre uma mutação de acordo com seu status, como a ordem de vendas que se transforma no produto final alocado no estoque da companhia.

Ao desfazer a complexidade do acompanhamento de todo o processo de produção, venda e faturamento, a empresa tem mais subsídios para se planejar, diminuir gastos e repensar a cadeia de produção. Um bom exemplo de como o ERP revoluciona uma companhia é que 
com uma melhor administração da produção, um investimento, como uma nova infraestrutura logística, pode ser repensado ou simplesmente abandonado. Neste caso, ao controlar e entender melhor todas as etapas que levam a um produto final, a companhia pode chegar ao ponto de produzir de forma mais inteligente, rápida e melhor, o que, em outras palavras, reduz o tempo que o produto fica parado no estoque.

A tomada de decisões também ganha outra dinâmica. Imagine uma empresa que por alguma razão, talvez uma mudança nas normas de segurança, precise modificar aspectos da fabricação de um de seus produtos. Com o ERP, todas as áreas corporativas são informadas e se preparam de forma integrada para o evento, das compras à produção, passando pelo almoxarifado e chegando até mesmo à área de marketing, que pode assim ter informações para mudar algo nas campanhas publicitárias de seus produtos. E tudo realizado em muito menos tempo do que seria possível sem a presença do sistema.

Entre os avanços palpáveis, podemos citar o caso de uma indústria média norteamericana de autopeças, situada no estado de Illinois, que conseguiu reduzir o tempo entre o pedido e a entrega de seis para duas semanas, aumentando a eficiência na data prometida para envio do produto de $60 \%$ para $95 \%$ e reduzindo as reservas de insumos em $60 \%$. Outra diferença notável: a troca de documentos entre departamentos que demorava horas ou mesmo dias caiu para minutos e até segundos.

Esse é apenas um exemplo. Porém, de acordo com a empresa, seria possível direcionar ou adaptar o ERP para outros objetivos, estabelecendo prioridades que podem tanto estar na cadeia de produção quanto no apoio ao departamento de vendas como na distribuição, entre outras. Com a capacidade de integração dos módulos, é possível diagnosticar as áreas mais e menos eficientes e focar em processos que possam ter o desempenho melhorado com a ajuda do conjunto de sistemas.

Os sistemas integrados dão às empresas a flexibilidade para responder rapidamente as solicitações dos clientes e ao mesmo tempo, produzir e manter em estoque apenas o necessário para atender aos pedidos existentes. Sua capacidade de tornar a expedição mais veloz e precisa, minimizar os custos e aumentar a satisfação do cliente também gera mais lucratividade as empresas.

Faço um comentário crítico com relação à integração: Tomo dois itens das Desvantagens:

Torna os módulos dependentes uns dos outros, pois cada departamento depende das informações do módulo anterior, por exemplo. Logo, as informações têm que ser 
constantemente atualizadas, uma vez que as informações são em tempo real, ocasionando maior trabalho;

Inserção de dados não confiáveis, quando é necessário o input pelo usuário;

Estes dois itens, para quem conhece e desenvolve Sistema Integrado de Gestão, é a prova real de este ERP é interligado e nunca integrado. No Sistema Integrado de Gestão os módulos interagem, interdependem e inter-relacionam e não tem este dois e outros problemas. Todos os dados se entendem de modo automático e, a cada entrada de dados, a posição dos relatórios gerenciais são automaticamente atualizados (LAUDON, 2007).

\section{ESTUDO DE CASO}

Neste capítulo iremos analisar através do Estudo de Caso, as etapas do processo do rollout SAP na empresa estudada. O foco desse estudo será os impactos e risco gerados durante a fase de implantação do sistema. Para tanto, foram utilizados levantamentos e questionários aplicados junto aos usuários chaves e aos gerentes de projeto.

\subsection{CARACTERIZAÇÃO DA EMPRESA}

A empresa estudada foi criada em 1939, após a descoberta de depósitos de magnesita em Brumado, no estado da Bahia. Suas atividades industriais começaram em 1944, em Contagem (MG), com a produção de refratários aluminosos e sílico-aluminosos e, a partir de 1948, produzindo também magnesianos e cromo-magnesianos. É uma empresa brasileira de capital privado, com ações negociadas em bolsa, dedicada à mineração, produção e comercialização de extensa linha de materiais refratários: são mais de 13 mil tipos diferentes, de materiais monolíticos e tijolos convencionais a cerâmicas nobres, para revestir equipamentos que operam em altas temperaturas. Os produtos são utilizados, principalmente, pelos fabricantes de aço, cimento e vidro.

Atualmente, a empresa opera 28 unidades industriais e de mineração, sendo 16 no Brasil, três na Alemanha, três na China, uma nos Estados Unidos, duas na França, uma na Bélgica, uma em Taiwan e uma na Argentina, com capacidade de produção de refratários superior a 1,4 milhão de toneladas por ano. A empresa estudada é a terceira maior produtora de refratários no mundo e líder em soluções integradas em refratários. 


\subsection{SISTEMA ERP}

De acordo com a gerencia do projeto o processo de definição de rollout para as plantas da França e Alemanha, surgiram para maior valorização e transparência da empresa para os investidores, e clientes, e principalmente uma interligação entre as operações do Brasil e Europa.

No início de 2011 a empresa enviou um RFP (requisição funcional de proposta) ao mercado para que as empresas respondessem para primeira análise da equipe de seleção (Planejamento e Requisitos).

De acordo com a RFP, a proposta está compreendida de acordo com o sistema SAP ECC v.6.0, produto da SAP AG, e que foi projetado para atender às necessidades específicas dos negócios. É uma solução que permite agilidade, maior eficiência, atingindo assim rápido retorno dos investimentos.

Ao contrário das demais soluções do mercado, o SAP ECC ajuda no gerenciamento de todas as áreas: desde finanças, recursos humanos, suprimento, estoque, produção, logística, desenvolvimento de produtos, serviços corporativos e até atendimento a clientes, vendas e marketing - em uma solução configurável. É a melhor opção para empresas que buscam uma solução ampla e integrada, facilitando o gerenciamento dos negócios do início ao fim.

Como escopo está compreendido os seguintes módulos SAP:

- SAP MM - Material Management

- SAP WM - Warehouse Management

- SAP SD - Sales andDistribution

- SAP FI - Financial Accounting

- SAP PP - Production Planning and Control

- $\quad$ SAP PS - Project System

- $\quad$ SAP CO - Controlling

- SAP QM - Quality Management

- SAP PM - PlantMaintenance

Em meados de 2011, após a análise das propostas das empresas de consultoria, a empresa definiu como prestadora de serviços de consultoria a empresa MOB (nome fictício).

Estavam presentes na reunião de aceite da proposta por parte da empresa, o VicePresidente e Sponsor do Projeto, o Diretor de TI, o Gerente de Projetos, e por parte da MOB, o Diretor Executivo e o Gerente.

Segundo o Gerente de Projetos, a empresa decidiu pela MOB pelos seguintes motivos: 
- Empresa reconhecida mundialmente por implantações SAP;

- Por ter apresentado vários cases de implantação do SAP em empresas do ramo de refratário, mineração e siderurgia;

- Maioria de consultores, $80 \%$ em CLT (menor risco de o consultor abandonar o projeto);

- Empresa possui vários prêmios de melhor implantador SAP;

- Melhor Custo/Benefício;

- Empresa sólida e organizada, certificação CMMI 3;

- Passou confiança a Diretoria e ao grupo avaliador quanto aos trabalhos a serem realizados;

O contrato foi firmado, e o projeto de rollout do SAP teve seu início programado para janeiro/2013.

\subsection{METODOLOGIA DE IMPLANTAÇÃO}

A metodologia utilizada para o rollout do sistema na França e Alemanha foi o método ASAP.

Em 1996, a SAP introduziu o Accelerated SAP (ASAP), a metodologia de implementação do sistema SAP R/3, com o objetivo de diminuir o tempo de implementação dos projetos numa organização. O ASAP é uma metodologia estruturada que facilita a adesão dos utilizadores ao sistema, com um roadmap bem definido, eficiente documentação nas várias fases que a compõem. A metodologia ASAP disponibiliza aos novos clientes acesso à experiência e ao conhecimento acumulados pro meio dos projetos de implementações a nível mundial. O ASAP unifica todo um processo de implementação, de modo a alcançar a missão crítica das funcionalidades do negócio da organização. (KALE, 2000).

O centro da metodologia ASAP é o roadmap, que consiste em um processo com cinco etapas que apoiam a empresa, desde da preparação inicial até à conclusão do projeto com a entrada em produtivo.

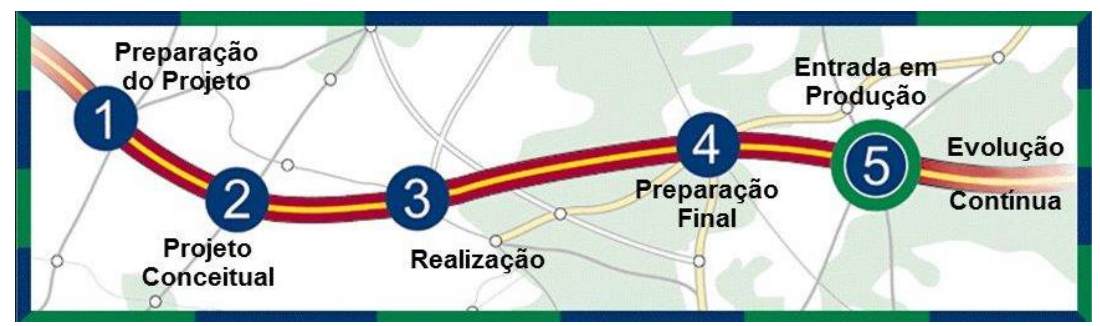

Fonte: Slide Share. 
As cinco fases que a compõem são:

- $\quad$ Preparação do Projeto;

- $\quad$ Análise dos Processos de Negócio;

- Realização;

- $\quad$ Preparação Final;

- $\quad$ Entrada em Produtivo e Suporte

Os componentes que se destacam nesta metodologia são os roadmap de implementação, plano do projeto, melhorias contínuas, ferramentas e aceleradores, área de conhecimento, procedimentos dos processos de negócio e base de dados de perguntas e respostas (MILLER, 1999).

\subsection{ORGANIZAÇÃO}

A implementação foi conduzida pelos gerentes de projeto da EMPRESA e da MOB utilizando práticas do PMBOK para gerenciamento de projetos. As equipes foram estruturadas por conhecimento/área. As pessoas que tinham um maior conhecimento na função/área específica eram intituladas como donos dos processos (processowner). Os usuários chaves (keyusers) acompanharam os donos dos processos no desenho da solução e, a partir da fase de realização, assumiram o projeto com os testes unitários, integrados, e com a realização de treinamentos.

No entanto, sempre que surgia uma discrepância entre o sistema e os processos do departamento, a responsabilidade por mudanças de processos das áreas era do próprio gestor da área ou dono do Processo. Os keyusers poderiam até identificar, mas sempre a homologação era do dono do processo.

Já a equipe técnica era composta, por consultores da MOB, e analistas de TI da empresa estudada.

Abaixo segue o organograma do projeto: 


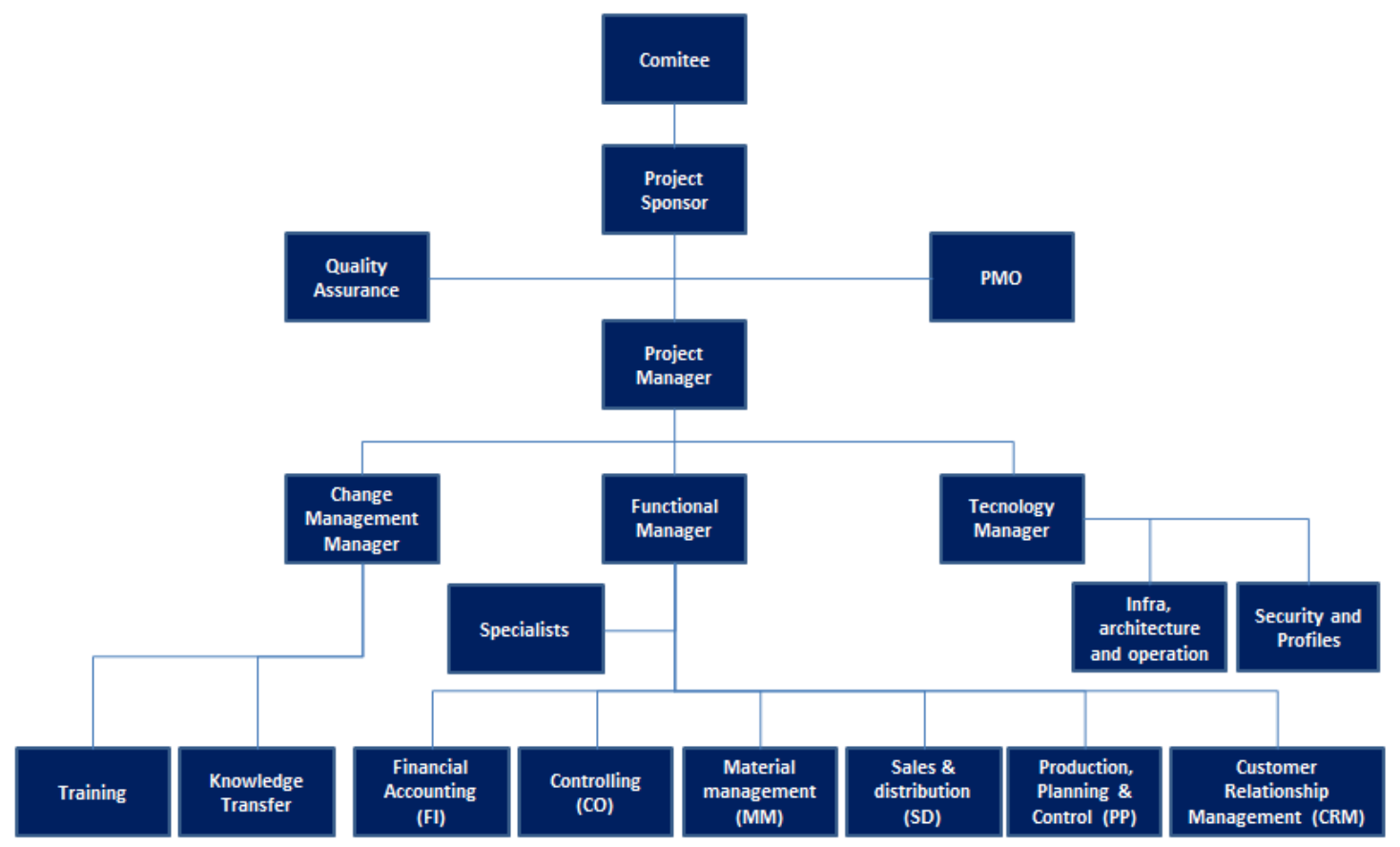

Fonte: $\mathrm{O}$ autor.

A seguir, é apresentada a descrição das equipes de organização a ser formada pela empresa estudada, e os profissionais da MOB.

Comissão: formado por diretores executivos da empresa estudada, e por um membro do executivo da MOB. Sua finalidade é assegurar a liderança e as decisões necessárias para o projeto, seguindo-se o desenvolvimento do trabalho através de reuniões periódicas (uma vez por mês), que aprova os produtos gerados pelo projeto e também presta serviços de gestão em pontos críticos.

Patrocinador do projeto: O membro do executivo da MOB, que é responsável por resultados positivos do projeto antes da empresa estudada, é o interlocutor do patrocinador do projeto em todos os assuntos relacionados com o progresso do trabalho.

Gerentes de Projeto: consiste no grupo composto por executivos da MOB e da empresa estudada. Esses profissionais asseguram a realização dos objetivos acordados pelo Comitê: prazo, custo, escopo e qualidade, e fazem o planejamento e controle do programa de trabalho, e gerenciamento da equipe do projeto.

Gerente Funcional, equipe e especialistas: é dirigido por um recurso MOB. Para todas as seguintes equipes funcionais haverá consultores da empresa estudada e a MOB. Esta equipe tem como objetivo definir os processos de negócios, para criar protótipos e implementar o sistema de acordo com a estratégia previamente determinada, garantindo o cumprimento dos termos e a qualidade dos produtos gerados. Deve também realizar a conversão, testes e treinamento dos multiplicadores, entre outras tarefas. 
Gerente de tecnologia e equipe: é formado por recursos da empresa estudada e a MOB, e é responsável pela tecnologia do projeto (gestão do ambiente SAP, servidores, software, impressoras, links de comunicação, estações de trabalho)

Gerente de Gestão de Mudança e equipe: é formado por recursos da empresa estudada e a MOB. O seu objetivo é planejar, gerenciar e realizar as atividades do projeto relacionadas ao: alinhamento executivo, os usuários de treinamento, comunicação interna e externa, teste de aceitação do usuário, suporte de pós-conversão, liderança e patrocínio. Conselheiro do gerente de projeto nas atividades de integração e motivação da equipe do projeto.

\subsection{PRAZO}

Quanto ao prazo do projeto, este sim foi um dos maiores desafios. Inicialmente o rollout SAP Europa (França e Alemanha) foi determinado para ocorrer no prazo máximo de 8 meses de projeto. Devido a diversos problemas de gestão o projeto atrasou, e se estendeu por mais 6 meses.

Isso quer dizer, que após dois replanejamentos (no-go), o sistema deu Go Live, sem maiores impactos, em agosto de 2015.

\subsection{DIFICULDADES ENCONTRADAS}

Por meio de aplicação do questionário aos usuários-chave, foram detectadas as seguintes dificuldades durante as fases de implantação e/ou utilização do SAP:

\section{a) Usabilidade do sistema:}

Segundo o keyuser de Compras: "o SAP é um sistema bastante complexo, com diferentes telas e mecanismos [...] navegar em suas telas e entender o que exatamente será útil àquela tela ou aplicação do módulo de MM.”

Conforme o depoimento do usuário-chave da área de compras, o maior problema que percebo, é a falta de conhecimentos profundos sobre o sistema, que permitam analisar melhor os problemas do dia-a-dia. Durante a utilização surgem dúvidas ou problemas que requerem análise e solução de forma adequada à filosofia do sistema, e que por diversas vezes demanda que o usuário pesquise e descubra qual é a solução. 
Para o Diretor de Compras e Logística, "a maior dificuldade é compreender a forma de trabalho que o ERP impõe, totalmente diferente da praticada até então”.

O Gerente do Projeto também concorda quando afirma: "a interface do SAP não é muito ergonômica e nem amigável, que trouxeram também dificuldades para os usuários na utilização".

\section{b) Diferenças culturais:}

Segundo o consultor de MM da MOB, "um dos maiores impactos que vi nesse projeto, foi a diferença cultural entre alemães, brasileiros e franceses. Acho que a própria gestão do projeto não esperava que isso poderia trazer tanto impacto para o projeto"

O Gerente do Projeto, por parte da MOB, também tece críticas nesse sentido: "realmente era algo que estávamos esperando, porém não estávamos imaginando um impacto tão grande no cronograma devido a este fato".

\section{c) Resistência dos usuários:}

De acordo com o consultor de PP da MOB, "considero um dos principais impactos no projeto, a resistência dos usuários em passar informação, e processos. Acredito que o maior medo deles é que o SAP seja implementado, e muitas pessoas perca o emprego".

Concordo com os comentários do consultor de PP, vejo isso como um grande desafio para os gerentes de projeto, pois um dos principais motivos de atraso em projetos, é devido os usuários não estarem preparados, e motivados para trabalharem, e contribuírem positivamente para o projeto.

Já o gerente do projeto por parte da empresa informa o seguinte: "não vejo isso como justificativa que contribuía para atrasar significativamente o projeto".

\section{d) Falta de treinamento por parte da consultoria:}

Os keyusers citaram a falta de testes integrados e informações básicas a respeito do sistema.

Conforme relato da keyuser de Vendas e Distribuição, "Algumas transações e procedimentos não foram treinados nos testes integrados, e que somente com a necessidade da utilização vão aparecendo as dificuldades, um exemplo disso foi referente às datas do sistema 
(data do documento e data do lançamento) que deu um retrabalho para colocar tudo em ordem, gerando vários estornos e lançamentos. As transações foram treinadas isoladamente, onde deveriam de ser treinadas num processo/sequência geral, o que aconteceu, foi que os usuários sabiam "como" fazer as transações no sistema, mas acabavam não sabendo "quando" e "onde" utilizá-las".

\section{e) Tempo de dedicação ao projeto:}

Outro ponto destacado por alguns usuários, principalmente do setor Administrativo/Financeiro, foi a falta de tempo para dedicação ao projeto. Segundo o usuáriochave de Contas a Pagar, "São várias dificuldades que acontecem em um projeto grande e trabalhoso como este, porém acredito que as maiores foram ter que participar da implantação do ERP sem abandonar as atividades diárias". Este problema foi percebido também por outros usuários, como é o caso do keyuser de Controladoria, que aponta: "Maior comprometimento do departamento financeiro" como um ponto que poderia ter sido melhorado no projeto.

Para o Diretor do departamento Administrativo-Financeiro, "as maiores dificuldades foram a dupla jornada de trabalho (utilizando duas ferramentas distintas), desconhecimento total da nova ferramenta, cronograma respeitado à força, testes realizados de forma precária".

\section{f) Gerenciamento do escopo:}

O gerenciamento de escopo inclui os processos necessários para garantir que o projeto considere somente o trabalho necessário para sua finalização com sucesso, e nada mais que isso. O gerenciamento do escopo está relacionado principalmente com a definição e controle do que está e do que não está incluso no projeto (PMBOK, 2008).

Um ponto considerado crucial para o atraso do projeto foi as redefinições do escopo durante a fase de realização, ou testes do sistema. Muitos processos foram mal definidos, e outros que nem foram pensados, e compartilhado com o projeto na fase de desenho.

O gerente do projeto informou, "Considero este ponto como o mais crítico, ele foi o responsável por $90 \%$ do atraso do projeto".

\section{g) Planejamento de recursos}


Devido ao baixo custo do projeto, e falta de apoio dos stakeholders, foi necessário diminuir o número de recursos da consultoria para conseguir atingir os valores contratuais impostos pelo cliente. Isto fez com que a equipe ficasse sobrecarregada, e contribuiu para o atraso, e sobreposição de algumas atividades durante a fase de implantação do projeto.

\subsection{BENEFÍCIOS DO SAP NA EMPRESA}

\section{a) Globalização dos processos}

Com o rollout do SAP para as unidades da França e da Alemanha, foi possível que a empresa ajustasse, e tornasse os seus procedimentos globalizados. Segundo o diretor de tecnologia, "é impressionante como o sistema facilitou e integrou as operações das filias da Europa com o resto da companhia. Agora, conseguimos enxergar mais transparência nos processos, e rapidez nos relatórios enviado aos investidores".

\section{b) Maior controle financeiro}

A utilização do ERP permitiu um controle orçamentário mais eficiente. Após o rollout do SAP as despesas não podem ser mais lançadas sem que haja verba aprovada para um centro de custo. Cada suplemento de orçamento fica registrado, facilitando a posterior análise das despesas orçadas vs. despesas realizadas e os desvios.

Segundo o keyuser da Controladoria, "Controle exato do orçamento. Exatidão do que é gasto com viagens de negócios da empresa, folha de pagamento, etc são benefícios gerados pelo SAP. Outro ponto positivo, é a velocidade que os dados são processados e compilados. Após a implantação, consigo enviar relatórios para a matriz da empresa com os dados referente ao fechamento contábil mensal em fração de segundos".

\section{c) Integração}

Com a implantação do ERP, houve a integração do Administrativo/ Financeiro com a Contabilidade e Controladoria. A informação é instantânea, há muita agilidade no tratamento dos dados. Os erros são rapidamente identificados e corrigidos. Quando o Contas a Pagar lança uma despesa, por exemplo, a Controladoria já enxerga essa despesa alocada na sua devida área de negócio.

Já na área de compras, o fluxo se tornou mais dinâmico. De acordo com o Gerente da área de compras, "Sinceramente, no início tivemos medo, pois nossos processos, e sistemas 
estavam implementados a anos e nunca tinha nos trazido problemas. Com a entrada do SAP pode-se perceber que o automatismo realmente funciona, e a agilidade e integração das informações são impressionantes. Ainda temos alguns problemas, porém o resultado foi satisfatório para toda equipe".

\section{d) Automação}

Muitos processos tornaram-se automatizados, não necessitando da intervenção manual de nenhum funcionário, o que acabou por minimizar a possibilidade de erros. Como exemplos, podem ser citados:

- a retenção de impostos nas invoices emitidas;

- importação dos arquivos da folha de pagamento;

- transferência entre os sistemas de produção e o SAP.

- exportação dos dados de compras para o setor de contas a pagar, entre outros.

\section{e) Competitividade no Mercado}

De acordo com o direto de tecnologia após a implantação do SAP em todas as filias da companhia (Brasil, China, Argentina, USA, Alemanha e França) a empresa se torna mais competitiva, e mais valorizada perante os seus concorrentes. "Hoje temos um sistema que está alinhado com as melhores práticas mundiais, posso dizer que literalmente estamos globalizados, e preparados para atender a qualquer demanda vinda dos nossos clientes".

\section{RESULTADOS OBTIDOS}

Com base no que foi relatado até o momento sobre o rollout do sistema ERP SAP na empresa estudada foipossível realizar a análise final dos principais pontos abordados. A começar pelo principal ponto, no caso, a estrutura de processo da organização mal definida.

Como já falado anteriormente, a empresa estudada adquiriu empresas de menor porte ao redor do mundo, dentre elas as empresas estudadas neste trabalho, as filiais situadas na França e na Alemanha.

Após a compra, e antes mesmo de iniciar o projeto de rollout do SAP, deveria ter sido efetuado um estudo, e principalmente o ajuste e padronização dos processos. Isso ficou nítido quando na entrega do projeto, o que deveria ter se tornado um sistema com usabilidades global, acabou se tornando um sistema com a maioria das funcionalidades locais. 
Se os procedimentos tivessem sido globalizados antes do projeto, seria possível se obter uma ferramenta mais sólida, e com custo e tempo de projeto reduzidos.

Por este motivo também foi possível observar que as alterações de escopo, e solicitação de novas demandas surgiam pela falta de conhecimento dos processos, e como estes processos poderiam ser adaptados no novo sistema.

Devido ao principal fato mencionado acima, este fez com que desencadeasse diversos outros problemas no projeto. Entre eles:

- Comunicação. Este seria o segundo maior problema analisado dentro do projeto. As equipes não se comunicavam, e a gestão não passava um report dos principais problemas e impactos.

- $\quad$ Prazo. Devido a alteração de escopo repentinamente, falta de alinhamento entre a gestão do projeto e membro das equipes, controle das atividades e sobreposição de tarefas, riscos não avaliados, e recursos insuficientes. Todos esses pontos foram cruciais para o atraso, e impacto significativo no cronograma do projeto.

- Escopo não definido. Mencionado em praticamente todos os itens, porém considerado um dos principais problemas encontrados no projeto. Principalmente, pelo fato da gestão, principalmente pelo cliente, não conseguir conter alterações ou inclusos de novas soluções nas fases consideradas críticas do projeto.

- Resistência dos usuários. Outro ponto considerado de impacto para o projeto. Neste caso, faltou principalmente uma parceira, e apoio da alta gestão da empresa estudada com a gestão do projeto. Visivelmente foi verificado que muitos usuários estavam desmotivados, e em discordância com a implantação de um novo sistema na empresa. Com isso, desde o início do projeto as informações eram ocultadas pelos usuários, o que impactou diretamente na definição do escopo, e andamento do projeto.

- Treinamento. Devido todo impacto ocorrido durante a fase de realização, a gestão novamente errou em não assumir atraso, e resolveu arriscar a fase de preparação final realizando treinamentos com funcionalidades inacabadas, e com conteúdo mal elaborados. Conclusão: Usuários mal preparados, e impactos nos primeiros dias do Golive.

- No-Go. Total de dois adiamentos do start do sistema. Este foi o resultado, devido a uma gestão não eficaz. Este processo acarretou novos custos para o projeto, e novos replanejamentos de atividades. 
Se todos os itens mencionados acima fossem planejados, executados e controlados com total eficácia, todos os resultados e metas seriam atingidos de acordo com o esperado, e consequentemente o custo e o sucesso do projeto seriam diferenciados.

\section{CONSIDERAÇÕES FINAIS}

Este estudo comprovou a dificuldade para se implementar, um projeto com qualidade, e principalmente ter o reconhecimento do cliente. Vale lembrar, que quando implementado um projeto de rollout estamos interferindo diretamente no trabalho de milhares de pessoas, e nas áreas de uma companhia. Muitos consideram a mudança como um benefício, porém a grande maioria sempre questiona sobre a necessidade da implantação e principalmente os benefícios que ela poderá trazer para o seu dia a dia.

No projeto estudado é possível analisar um conjunto de falhas ocorridas por falta de um bom gerenciamento. $\mathrm{O}$ item considerado mais crítico foi a falta de comunicação, e o comprometimento da alta direção da empresa com o projeto. Sem credibilidade os próprios usuários e gerentes estavam fazendo o que queriam no projeto. Sem essa percepção o gerente perdeu completamente o controle do projeto, e os problemas a cada dia aumentando.

Foram decisivos para o impacto no cronograma:

Alteração do escopo: Desde o início o projeto não tinha uma definição clara de todos os processos que rodavam nas empresas da França e Alemanha. Todos acreditavam que por ser um rollout global, todos os processos se encaixariam perfeitamente conforme a matriz (Brasil). Com o passar do tempo, observamos que as alterações e novas definições foram se tornando cada fez mais frequentes, porém por não terem um controle de risco adequado, todas as demandas acabaram se tornando urgentes, o que impactou diretamente nos entregáveis das fases, e principalmente no custo do projeto.

Desenho de Processo: Este também é considerado como outro ponto crítico dentro do projeto. Por falta de experiência, a empresa estudada acreditou que poderia ser efetuado um projeto de rollout global de um sistema ERP, porém sem ter que redefinir, e globalizar os processos da companhia. Este processo foi crucial para gerar impactos, principalmente no que se referiam as soluções locais utilizadas especificamente na Alemanha e França.

Cultura: Por se tratar de países diferente, a empresa estudada juntamente com a equipe da consultoria terem efetuado um trabalho de integração e principalmente de acompanhamento junto com a equipe de gestão da mudança para entender, e mapear os riscos que o projeto poderia ter pela diferença da cultura das pessoas envolvidas com o projeto. O principal motivador para isso é a relação entre as variáveis "tempo" e“entrega". A equipe global 
Brasileira sempre disposta e motivada em fazer hora extra, e tentando ao máximo entregar as atividades no tempo determinado no cronograma. Enquanto a equipe Europeia se preocupava mais com a qualidade, e a definição dos processos bem definidos, porém tinham pouco comprometimento com o projeto, e principalmente em seguir o que estava no cronograma.

Tempo de implementação: Não se deve iniciar um projeto sabendo que o prazo definido para seu término está aquém do prazo realmente necessário para sua realização. Reduzir o prazo total do cronograma por pressão do cliente foi o pior dos erros que o gerente do projeto poderia ter cometido, pois acabou sendo conivente com a ingerência do cliente, assumindo para si todos os riscos do não cumprimento dos prazos. Neste caso, a melhor saída teria sido negociar com cliente, provando que ele estava errado em sua previsão;

Mapeamento dos Riscos: Correr riscos faz parte de qualquer negócio. Mas, menosprezar os riscos potenciais em um projeto é a pior das imprudências. Comprovando esta afirmação temos o módulo de gestão de risco como o mais extenso do PMBOK. Portanto, antes de qualquer decisão ou definição no projeto, deve-se reavaliar o plano de risco. Nesse Projeto, atitudes como aceitar prazos audaciosos e ser complacente com a falta de expertise da equipe foi o mesmo que virar as costas para os riscos do projeto;

Diante de todos os fatos mencionados, é possível concluir que o atraso de sete meses do projeto está justificado, e os custos extraordinários deram-se em decorrência de uma gestão ineficiente e despreparada para administrar um projeto de rollout SAP de um time global. 


\section{REFERENCIAS}

CHERENE, Lumena Paes; SILVA, Luciano Souza; SILVA, Simone Vasconcelos. Dificuldades e benefícios na implementação de um sistema de gestão empresarial (Sap R/3). Perspectivas OnLine, $\quad$ v. $4, \quad$ n. $16, \quad 2010.4$ Disponível em: http://www.seer.perspectivasonline.com.br/index.php/revista_antiga/article/view/459/364. Acesso em: 12 out. 2018.

FERREIRA, Adhemir; COUTO, Celso; MICCHELUCCI, Andrea. Aquisição de Sistemas ERP: uma an.álise dos resultados obtidos pelas empresas. Gestão Contemporânea, n. 9, p. 87$101,2011$.

FERRARI, Afonso Trujillo. Metodologia da pesquisa científica. São Paulo: Mc Graw-Hill do Brasil, 1982.

GIL, Antônio Carlos. Como elaborar projetos de pesquisa. 4. ed. São Paulo: Atlas, 2002.

LAKATUS, Eva Maria; MARCONI, Marina de Andrade. Metodologia do trabalho científico: procedimentos básicos, pesquisa bibliográfica, projeto e relatório publicações e trabalhos científicos. 5. ed. São Paulo: Atlas, 2001.

LAUDON, Kenneth C. Sistemas de Informação Gerenciais. 7. ed. São Paulo: Editora Afiliada, 2007.

LAUDON, Kenneth C. Sistemas de informações gerenciais: Administrando a empresa digital. São Paulo: Prentice Hall, 2004.

LAUDON, Kenneth; LAUDON Jane. Sistemas de informação. 9. ed. São Paulo: Prentice Hall, 2010.

LUCAS, Henry C. Tecnologia da Informação. 13. ed. Rio de Janeiro: LTC Editora, 2006.

MESQUITA, Robson Antônio Catunda. Sistemas ERP (Enterprise Resource Planning). Brasília: Centro Universitário de Brasília - UNICEUB: [200?].

MILTELLO, K. Quem precisa de um ERP? Info Exame, p. 140, mar. 1999.

MILLER, Stewart. SAP R/3 Certification Exam Guide. New York: MC Graw Hill, 1999.

O'BRIEN, James A. Sistemas de Informação e as decisões gerenciais na era da Internet. 2. ed. São Paulo: Saraiva, 2004.

O'BRIEN, James A.; MARAKAS, George M. Administração de Sistemas de Informação. 15. ed. Porto Alegre: AMGH, 2013.

O'BRIEN, James A. Administração de Sistemas de Informação: uma introdução. 13 ed. São Paulo: Mc Graw Hill, 2007. Cap. 7.

PADILHA, Thais Cássia Cabral; MARINS, Fernando Augusto Silva. Sistemas ERP: características, custos e tendências. Revista Produção, v. 15, n. 1, p. 102-113, 2005. 
RAUPP, Fabiano M.; BEUREN, Ilse M. Metodologia da pesquisa aplicáveis às ciências sociais. In: BEUREN, Ilse M. (org). Como elaborar trabalhos monográficos em contabilidade: teoria e prática. São Paulo: Atlas, 2003. p. 76-97.

TURBAN, Efraim. Tecnologia da Informação para Gestão: em busca de um melhor desempenho estratégico e operacional. 7. ed. Porto Alegre: Bookman, 2010. p. 318-361.

VALENTIM, Onivaldo Aparecido. et al. Análise comparativa entre a implementação e atualização do sistema ERP SAP R/3 da SAP considerando os fatores críticos de sucesso descritos na literatura: um estudo de caso em uma empresa do segmento de bebidas. Gestão \& Produção, v. 21, n. 1, p. 111-124, 2014. 